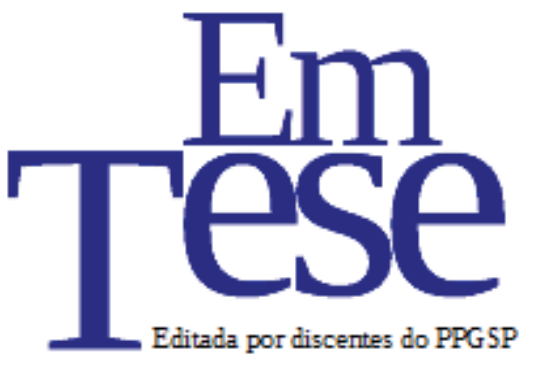

UFSC

PPG SP PROG RAMA DE

PÓS-GRADUAÇÃO EM

Sociologia Política

\title{
Coaching na aula de Sociologia
}

Paulo Carlos Silva ${ }^{1}$

Resumo: Este trabalho parte da hipótese de que o coaching, técnica bem conhecida no âmbito da administração e do esporte, poderá produzir bons resultados em sala de aula devido à sua proximidade com os objetivos de um educador que é o de conduzir seu aluno ao território do conhecimento. Inspirado na obra de Bernard Lahire, utilizei o método qualitativo conhecido como pesquisa-ação tendo como base ferramentas e técnicas de coaching para coleta de dados e intervenção na realidade através da provocação da auto avaliação do aluno e imediata tomada de uma decisão. Logramos êxito no aspecto de que, sendo de escola pública, mergulhados no senso comum de estarem em uma escola inferior, foram sensibilizados para a consciência de serem autores da própria história e assim motivá-los a buscar os caminhos para o sucesso.

Palavras-chave: Sociologia; Coaching; Ensino Médio.

\section{Coaching in Sociology classroom}

Abstract: This work starts from the assumption that coaching, well-known technique in the administration and sport, can produce good results in the classroom due to its proximity to the goals of an educator who is to lead your student to the territory of knowledge. Inspired by the work of Bernard Lahire, I used the qualitative method known as action research based on Coaching's tools and techniques based coaching for data collection and intervention in reality by provoking the self evaluation of the student and immediately making a decision. We gain success in the aspect that, being a public school, steeped in common sense of being in a lower school, were aware of the awareness of being authors of their own history and thus motivate them to seek paths to success.

Keywords: Sociology; Coaching; High School.

\footnotetext{
${ }^{1}$ Professor de Filosofia e Sociologia pertencente ao quadro efetivo da Rede Estadual de Ensino de Pernambuco. Mestre em Ciências Sociais pela Fundação Joaquim Nabuco (FUNDAJ). E-mail: prpaulocarlos@hotmail.com.
} 


\section{Introdução}

O presente artigo tem como objetivo relatar a experiência da utilização do coaching com alunos do Ensino Médio de uma escola da Rede Pública do Estado de Pernambuco, na disciplina de Sociologia, como uma ferramenta de auxilio pedagógico cuja finalidade é, além de motivá-los para lutarem em busca dos seus sonhos, ajudá-los a descobrir quais são seus pontos fortes e de melhoria, para com isso construírem estratégias de ações a fim de alavancarem seu desempenho acadêmico.

Essa experiência foi vivenciada durante os três primeiros bimestres do ano letivo de 2015 com cerca de 280 alunos, que estão divididos em turmas do $1^{\circ}, 2^{\circ}$ e $3^{\circ}$ ano do Ensino Médio, na Escola Estadual Conselheiro Samuel Mac Dowell, situada no bairro Jardim Primavera, pertencente à cidade de Camaragibe, região metropolitana do Recife. É importante ressaltar que essa área é pouco assistida por políticas públicas.

Parto da hipótese de que o coaching, técnica bem conhecida no âmbito da administração e do esporte, poderá produzir bons resultados em sala de aula devido à sua proximidade com os objetivos de um educador, que tem como tarefa principal conduzir seu aluno ao território do conhecimento. O coaching inspirado na Maiêutica, método socrático baseado no ato de perguntar ao seu interlocutor sobre a conceituação das coisas, busca não o constrangimento das pessoas em uma possível situação de ignorância sobre o que fora perguntado, mas intenciona libertá-lo de toda ilusão do pensar que sabe, para ajudá-lo a produzir o verdadeiro saber, condição fundamental para seu crescimento e futura independência. Independência, autonomia, liberdade, construídas através de diálogos significativos que se concretizam na fala e na escuta entre os sujeitos, são conceitos caros na obra do educador Paulo Freire e são fundamentais na prática do coaching.

Outro elemento fundamental para o coaching é a crença no potencial interno de cada indivíduo. Nesse aspecto, temos na Sociologia dois correspondentes de diálogo, a saber: Pierre Bourdieu e Bernard Lahire. Bourdieu desenvolveu o conceito de habitus, que seria um conjunto de disposições, ações e percepções internas forjadas ao longo do processo de socialização do indivíduo (SETTON, 2002). Para Bourdieu, o habitus fornece um repertório de ações que serão utilizadas a depender das relações sociais e do espaço que o individuo ocupe nessas relações. Essa ideia encontra eco no conceito de 
configuração defendido por Norbert Elias (ELIAS, 1994) no qual ele constata que o individuo assume posturas diferenciadas a depender do espaço social que ocupa. Por exemplo, uma pessoa casada que tenha filho e pais vivos assume postura e discursos diferenciados na relação de interdependência com seus interlocutores (pais, filho, esposa, sogra, cunhado, etc.). Nesse sentindo, o sucesso escolar estaria atrelado a um repertório de disposições e ações construídos antes da chegada do aluno à escola. A escola, que é um espaço social, exige certo padrão de comportamento. Segundo Bourdieu, seria a família a fonte principal da composição desse repertório que ele chama de capital cultural. Lahire (2004), que foi seu aluno, também defende que o sucesso escolar depende desse capital cultural, mas, ao contrário de Bourdieu, ele acredita que o repertório ou disposições internas exigidas pela escola podem ser despertados e construídos em muitos outros lugares fora da família, como um clube, uma igreja ou qualquer outro grupo social que forneça elementos de disciplina.

Neste sentido, acredito que a escola poderia ser não apenas um local de cobrança desse capital cultural, mas também um desses lugares capazes de despertar as disposições internas que ela mesma exige que o aluno tenha para alcançar o sucesso acadêmico. Assim, surge o coaching como auxílio para essa tarefa. Digo auxílio porque não é tarefa do coaching o ensino, isso é tarefa da escola, o coaching apresenta-se como parceiro.

Na prática, o processo de coaching promove a evolução em cada fase, pois a evolução surge de dentro e nunca pode ser ensinada de forma prescritiva. O coaching não é uma forma de ensino, mas tem que ver com criar as condições para aprendizagem e crescimento (WHITMORE, 2012, p. 12).

Dessa forma, este artigo está dividido da seguinte forma: na primeira parte, será tratado o conceito de coaching. Na segunda parte, será abordada a questão da razão pela qual a técnica foi escolhida para uso pedagógico no ensino de Sociologia no Ensino Médio. Em terceiro lugar, serão apresentadas as ferramentas de coaching as quais foram escolhidas para serem utilizadas em sala de aula. Em seguida, abordaremos os componentes teóricos que justificam o seu uso na prática de ensino. Em quinto lugar, relataremos um pouco da experiência em sala de aula. Por fim, a conclusão sinaliza os pontos positivos do uso da técnica e compartilha os resultados obtidos até agora. 


\section{O que é o coaching? Origem e desdobramento do conceito}

A origem da palavra inglesa coach é um tanto incerta. Uma das possíveis explicações encontra-se no século XVIII, quando se designava o condutor da carruagem de cocheiro, o qual levava os estudantes da nobreza inglesa para as Universidades (CELESTINO, 2015). Além dessa função, ele também treinava os cavalos para a tarefa de puxar a cabine de passageiros, chamada de coche ou Kócs, na língua húngara; língua na qual primeiro se cunhou o termo para a carruagem (MARQUES, 2015). Encontramos este termo de forma mais comum no campo dos esportes. Ele foi, e ainda é, utilizado nas universidades estadunidenses para designar os técnicos esportivos. Por fim, chegou ao meio empresarial como técnica para preparar liderança de elevado padrão e eficiência (WHITMORE, 2012). O coaching é baseado na parceria dos envolvidos, visando à conquista dos objetivos anteriormente combinados.

O coaching é uma relação de co-criação, travada numa ambiente de confiança e mutualidade entre o coach (profissional que coordenará o processo) e o coachee (contratante do serviço), das estratégias de ações que serão realizadas pelo cliente. Nesse processo, o primeiro ajuda o segundo a descobrir seus pontos de melhoria e potencializar suas forças, visando alcançar as metas sonhadas pelo cliente.

O coach utiliza como ferramenta principal o ato de perguntar, uma vez que as respostas para os anseios do coachee (o cliente ou o aluno) estão com ele mesmo. Portanto, o papel do coach é o de ajudar seu cliente a refletir sobre os seus conceitos e valores, para com isso reelaborar suas ações, tornando-as mais coerentes e eficazes.

Neste processo de reelaboração dos conceitos estabelecimentos a partir dos valores e da definição dos objetivos, o coach vai auxiliando o coachee nas ressignificações de experiências vividas, sempre apontado para o futuro. Nisto já encontramos uma diferença da abordagem psicoterapêutica que foca no resgate do passado como elemento do processo de cura. Enquanto o foco do coaching é o futuro, a meta, o alvo. Outra diferença do coaching em relação a outras abordagens está no fato da valorização do saber do coachee como elemento essencial para o progresso do processo. O coach não precisa ser especialista na área profissional do coachee, o coach só precisa fazer perguntas poderosas que levem o coachee a pensar sobre sua trajetória e suas opções. Perguntas poderosas são aquelas que levam o cliente a pensar sobre 
possibilidades que ainda não haviam sido cogitadas por ele, apesar de serem relativamente simples e transformadoras. O coachee (o cliente) sempre terá a forma correta de fazer as coisas e ele deve ser o dono do processo, pois as consequências das suas escolhas serão dele. O coach será o seu apoiador, seu motivador, mas sem esquecer-se da sua responsabilidade de fazer o coachee pensar sobre tudo e tomar as decisões de forma consciente e responsável. O coach também tem a tarefa de ajudar o coachee a identificar os obstáculos e fazê-lo pensar o modo de superá-los.

Após a identificação das metas, possibilidades e impedimentos formulam-se, em parceria, um plano de ação. O plano não visa exclusivamente o alcance de uma determinada meta, mas deve também visar à ressignificação do modo de ver os acontecimentos, ou seja, o cliente deve partir para a ação lembrando que não há fracassos, mas apenas resultados, e esses resultados são produtos de modos adequados ou não de se fazer uma determinada coisa, assim como acontece em uma pesquisa cientifica na qual a hipótese inicial poderá ou não se confirmar. Caso não se confirme isso não invalida o processo da pesquisa. Esta mudança de paradigma produz um individuo motivado, confiante, capaz de caminhar sozinho em qualquer situação e mais equilibrado nas elaborações dos conceitos sobre si e sobre os outros e pronto para enfrentar as possíveis decepções.

\section{Coaching e Sociologia}

A decisão de utilizar essa ferramenta teve como um dos motivadores a declaração de um aluno em sala de aula que não conseguia entender nada da matéria e que, portanto, ia esperar para fazer uma recuperação que seria, no seu entendimento, mais fácil.

Encontrei vários conceitos equivocados nessa declaração: em primeiro lugar, a crença do discente na sua incapacidade de compreensão. A questão que me veio foi: como um saber composto e transmitido por um ser humano não pode ser entendido por outro ser humano que tem o material escrito em sua língua materna? Em segundo lugar, percebo que a espera até a recuperação é um mau uso do tempo, na verdade é o desperdício de um tempo que não tem volta. Em terceiro lugar, vi que a sua esperança num sistema que deverá beneficiá-lo ao final do ano letivo é a entrega do destino da sua 
vida nas mãos do outro. A coragem daquele aluno de afirmar isso me despertou para uma realidade mais ampla. Alunos que, desmotivados ou desesperançados com a educação, têm sua presença, em sala, movida pelos benefícios governamentais (bolsa família ou cotas para universidades), mas sem perspectivas de crescimento ou interesse pelo conhecimento. Claro que isso não deve ser encarado como algo determinado e generalizado, nem tão pouco como um objetivo dessa política pública, mas como uma possibilidade de abordar a questão.

Sendo a Sociologia uma disciplina escolar que trata das questões sociais de um modo direto, estou convencido de que o aprofundamento das questões que ela levanta estimulará o aluno a buscar uma mudança do seu entorno e o coaching, além de despertar a consciência para esta necessidade, ajuda o aluno a construir seu caminho de forma segura.

Vejo ainda outra proximidade do coaching com a Sociologia, no aspecto que a segunda, a partir da abordagem dos elementos do cotidiano, visa a um processo de desnaturalização das questões sociais para o despertar de uma ação transformadora do individuo. O coaching também aborda questões do cotidiano, sejam elas coletivas ou individuais, que têm reflexo no coletivo.

Como vimos na introdução, o coaching também se aproxima da Sociologia através de Bourdieu (1992) e Lahire (2004), pelo aspecto da crença em um potencial interno que pode interferir no sucesso escolar. No caso de Bourdieu o conceito de habitus, em Lahire pelo conceito das disposições. Na sua obra Sucesso escolar nos meios populares: as razões do improvável, Lahire (2004) apresenta, entre outros elementos de interferência nos resultados escolares, a questão da presença de pessoas que se tornam referenciais de sucesso para o aluno, a presença motivadora da família e o uso disciplinado do tempo. Esses elementos são abordados no coaching como objetos para promover a autorreflexão do aluno.

\section{Descrição das ferramentas de coaching}

$\mathrm{Na}$ aplicação da técnica no âmbito pessoal e/ou profissional, o coach lança mão de uma centena de recursos para ajudar o coachee a alcançar seus objetivos. Nesta experiência em sala da aula, foram utilizadas três ferramentas acompanhadas de uma 
técnica que se ligam diretamente a um processo cujo tempo de duração está claramente definido por um calendário escolar. Resta-nos mapear os pontos de partida e de chegada dos conteúdos a serem adquiridos, o que deve coincidir com o início e o final de cada etapa do ano letivo. Essa primeira tarefa é vencida aplicando a Roda do Conhecimento, que nada mais é que um mapeamento do quanto cada aluno conhece dos conteúdos que serão ministrados durante aquele ano. As perguntas iniciais têm como objetivo a sondagem do nível da classe. Isso auxilia o professor no conhecimento da sua turma e descoberta dos possíveis desníveis entre os alunos, bem como objetiva a tomada de consciência da turma do quanto há para ser explorado e conhecido.

A segunda ferramenta, chamada de Tríade do Tempo, concretiza, no papel, o tempo que parece fluído. $\mathrm{O}$ ato de registrar quanto tempo se investe em fatos importantes, urgentes e circunstanciais visa conscientizá-los da importância do bom uso do tempo. Este registro explicita como cada um tem usado este bem precioso e não renovável de modo a convidá-los a produzir uma agenda que privilegie o uso do tempo de modo racional e produtivo. A Tríade do Tempo, bem aplicada, melhora inclusive a qualidade do tempo investido na diversão, sem abrir mão do comprometimento com o processo de aprendizagem. Processo este que não é só da responsabilidade do professor. Essa corresponsabilidade de ampliar o conhecimento é firmada no final da aplicação da Roda do Conhecimento. O nível de comprometimento e o acompanhamento desse acordo são realizados através da técnica chamada de Escala. O aluno é regularmente convidado a avaliar, numa escala de 0 a 10, o quanto ele está comprometido com o processo. Esse convite é feito de modo oral, numa conversa sem tom de ameaça, estimulando-o a refletir se os seus atos e hábitos fazem sentido ou estão em acordo com o compromisso assumido por ele anteriormente.

Essas ferramentas foram acompanhadas pela técnica chamada de Patrocínio Positivo. Essa técnica é utilizada durante todo processo de modo muito sincero, mas sempre que possível com muita ênfase. Ela consiste em palavras de estímulo e elogios visando à elevação da autoestima do aluno e o destaque das ações corretas, numa declarada ação de reforço aos atos positivos. Essa ferramenta é marcada por uma busca otimista pelas boas intenções, embora, em alguns casos, o resultado não tenha sido um dos melhores. Os "fracassos" devem ser encarados como um aprendizado de como as coisas não podem ser feitas. Em outras palavras, os maus resultados devem gerar 
perguntas sobre os processos e não sobre pessoas, pois as pessoas são capazes de lograr êxitos se conseguirem equalizar um processo de ação que faça sentido para elas. Neste sentido, uma palavra de incentivo sincero deve sempre brotar de toda e qualquer situação. Isso exige um olhar otimista para todo e qualquer cenário.

\section{Bases teóricas do método}

A base teórica da técnica de coaching é bastante ampla. Uma vez que o seu objetivo é lançar luz para a caminhada do indivíduo que se lança em parceria com o seu coach em direção à conquista dos seus objetivos, todo o saber humano até então acumulado torna-se matéria prima de trabalho. Contudo, para nortear o relato desta experiência em um espaço relativamente pequeno, propomos um recorte específico lastreando nossa prática em três fundamentos do coaching ligados à educação. O primeiro fundamento encontra-se na Maiêutica socrática. Como já foi dito na introdução, a Maiêutica socrática não tinha como objetivo trazer constrangimento aos seus interlocutores, embora isso ocorresse com aqueles que advogavam saber de tudo. Sócrates usava as perguntas para ajudar seus interlocutores a deparar-se com sua ignorância sobre determinados temas e assim partir em direção ao saber. Essa postura encontra-se na máxima do coaching que diz: "As perguntas são as respostas". A pergunta é a matéria prima do processo de coaching. Diferente da abordagem tradicional, que transforma a pergunta em uma ferramenta avaliativa do saber do aluno para a conquista de uma nota que será atribuída pelo professor, a pergunta, em um processo educacional mediado por técnicas de coaching, torna-se um dado para a reflexão do que precisa ser aprendido ou, caso o conteúdo já tenha sido abordado, quais as causas que têm dificultado a compreensão e os caminhos a serem tomados pelo aluno para superá-lo. Em outras palavras, perguntando, o professor-coach ajuda seu aluno a deparar-se com o grau de elementos desconhecidos que há em sua frente, como também o ajuda a descobrir os caminhos para resolução das questões, não só as questões teóricas da matéria, mas dos elementos que têm impedido seu avanço acadêmico, como o mau uso do tempo, por exemplo.

O segundo pilar que elegemos para esta comunicação está no romance de Jean Jacques Rousseau intitulado Emílio. Embora possa sofrer, entre outras, a crítica de não 
ser um caso real e sim, hipotético, e daí seguir-se uma série de críticas sobre a viabilidade de tornar Emílio um ser integrado à vida social depois de um longo período de isolamento, a obra carrega alguns elementos importantes encontrados na prática do coaching, entre eles o de empoderamento do aluno que, embora nasça, segundo Rousseau, bom, precisa de ferramentas para enfrentar a sociedade que tentará degenerálo.

\begin{abstract}
Nascemos fracos, precisamos de forças, nascemos desprovidos de tudo, temos necessidade de assistência; nascemos estúpidos, precisamos de juízo. Tudo o que não temos ao nascer, e de que precisamos adultos, é-nos dado pela educação. Essa educação nos vem da natureza ou dos homens ou das coisas (ROUSSEAU, 1995, p. 10).
\end{abstract}

Sem querer entrar na discussão, se a essência humana é boa ou má por natureza, o coaching tem como pressuposto que todo ser humano tem potencialidades $\mathrm{e}$ elementos de melhoria e o papel do coach é despertar essas potencialidades, as quais Lahire chama de disposições que, diferente da proposta de Rousseau, não se contrapõem a uma realidade objetiva externa, mas que são incorporadas e disparadas na relação de interdependência (LAHIRE, 2004).

Além disso, é preciso propiciar as condições necessárias para o livre agir do indivíduo na sociedade, dando-lhe uma base para que exerça o papel que melhor lhe convier.

$\mathrm{Na}$ ordem natural, sendo os homens todos iguais, sua vocação comum é o estado de homem; e quem quer seja bem educado para esses, não pode desempenhar-se mal os que com esse se relacionam. Que se destine meu aluno à carreira militar, à eclesiástica ou à advocacia pouco me importa. Antes da vocação dos pais, a natureza chama-o para a vida humana. Viver é o ofício que lhe quero ensinar (ROUSSEAU, 1995, p. 15).

Além do tema Liberdade, há outros elementos que Rousseau, através dessa obra, deixa como legado para a educação e também para o coaching, como por exemplo, a importância de conhecer o aluno e suas necessidades para que o processo educativo tenha sucesso, como fica claro nesse trecho da obra:

Não se conhece a infância; no caminho das falsas ideias que se têm, 
quanto mais se anda, mais se fica perdido. Os mais sábios prendem-se ao que aos homens importa saber, sem considerar o que as crianças estão em condições de aprender. Procuram sempre o homem na criança, sem pensar no que ela é antes de ser homem. (...) Começai, pois, por melhor estudar vossos alunos, pois com toda certeza não os conheceis (...) (ROUSSEAU, 2004, p. 4).

Seja ou não um texto sociológico, e mesmo sofrendo críticas pelo fato de tratarse de uma espécie de utopia social, a verdade é que esse romance ainda ocupa lugar nas bibliografias dos cursos de Pedagogia e de formação de professores. Embora este trabalho não seja diretamente ligado à Pedagogia, ele tem um olhar para a formação de professores.

É este empoderamento, encontrado em Rousseau e instigado pelo coaching, que promove a liberdade de ação e faz a ponte para o terceiro pilar teórico. O terceiro fundamento teórico encontra-se em Paulo Freire, que propõe uma educação libertadora. Uma educação que se constrói socialmente em um processo dialético e não por uma doação de saber de modo unilateral. Pois, segundo o autor dos livros Pedagogia da autonomia (1997a) e Pedagogia do oprimido (1997b), os alunos trazem saberes para a sala de aula que devem ser levados em conta sem que o professor abra mão de uma estrutura que assegure o avanço acadêmico de modo eficiente e metodologicamente marcado. Essa educação exige escuta. Afinal, se há uma pergunta, a resposta precisa ser ouvida atentamente.

No processo da fala e da escuta, a disciplina do silêncio a ser assumido com rigor e a seu tempo pelos sujeitos que falam e escutam é um sine qua non da comunicação dialógica. O primeiro sinal de que o sujeito que fala sabe escutar é a demonstração de sua capacidade de controlar não só a necessidade de dizer a sua palavra, que é um direito, mas também o gosto pessoal, profundamente respeitável, de expressá-la. Quem tem o que dizer tem igualmente o direito e o dever de dizê-lo. É preciso, porém, que quem tem o que dizer saiba, sem sombra de dúvida, não ser o único ou a única a ter o que dizer. Mais ainda, que o que tem a dizer não é necessariamente, por mais importante que seja, a verdade alvissareira por todos esperada. É preciso que quem tem o que dizer saiba, sem dúvida nenhuma, que, sem escutar o que quem escuta tem igualmente a dizer, termina por esgotar a sua capacidade de dizer por muito ter dito sem nada ou quase nada ter escutado (FREIRE, 1997a, p. 73).

Essa é a alma coaching. Um saber construído tendo como base a realidade, mas 
com um olhar crítico e proativo. Uma co-criação lastreada na escuta comprometida. Não há no coaching, como não há em Paulo Freire, a ideia fatalista da realidade, cuja única saída que resta é esperar o futuro acontecer sem qualquer possibilidade de intervenção. Foco no futuro é um dos fundamentos do coaching. Futuro esse que, segundo Freire, pode ser formulado e reformulado sempre na perspectiva de um avanço contínuo em direção de um futuro que ainda está por ser escrito.

\section{Uma experiência bem sucedida}

Entendendo que o processo de educar, vai além do transmitir novos conteúdos aos educandos, segundo já afirmou Freire em suas obras,

É preciso insistir: Este saber necessário ao professor - que ensinar não é transferir conhecimento - não apenas precisa ser apreendido por ele e pelos educandos nas suas razões de ser - ontológica, política, ética, epistemológica, pedagógica, mas também precisa ser constantemente testemunhado, vivido (FREIRE, 1997b, p. 27).

E seguindo a orientação dada por Jean Jacques Rousseau (1995) de procurar conhecer seus educandos, iniciamos um processo de levantamento da situação motivadora da presença dos alunos em sala de aula. Queríamos saber qual ou quais os motivos que os traziam todos os dias para a escola. Que sonhos ou expectativas eles alimentavam tendo como base sua vida acadêmica. Que sentido fazia para eles os conteúdos trabalhados, e se eles conseguiam aplicá-los no dia a dia. As respostas foram as mais variadas, mas o que predominou foi a ausência de sonhos ou expectativas sobre um futuro promissor. A maioria não tinha pensado em sua vida como um projeto de médio ou longo prazo. A maioria estava ligada ao hoje, e como as condições sociais, no geral, não thes eram favoráveis, não conseguiam vislumbrar um horizonte de oportunidades. Também identificamos uma autoimagem negativa construída ou assumida de um discurso massificado na sociedade de que escola pública não é boa o suficiente para capacitar seus alunos para concorrer com alunos de escolas particulares; que os alunos de escola pública não querem estudar ou são incapazes de assimilar a mesma carga de conteúdo que um aluno de escola particular.

Diante desse cenário pessimista, propus aos alunos uma reflexão sobre propósito 
de vida a partir da exibição de uma animação baseada no livro que tem o mesmo título do filme, a saber: Quem comeu o meи queijo?

Partindo do pressuposto defendido por Geertz em A interpretação das culturas, quando em conclusão da ideia que o homem é carente de símbolos diz:

O homem precisa tanto de tais fontes simbólicas de iluminação para encontrar seus apoios no mundo porque a qualidade não-simbólica constitucionalmente gravada em seu corpo lança uma luz muito difusa (GEERTZ, 2008, p. 33).

Iniciamos o debate sobre a construção social como uma elaboração simbólica que visa a dar sentindo à existência. Os alunos foram compartilhando experiências que fizeram eco nas figuras das personagens do filme. Ora eles se sentiam motivados a lutar ora eles não viam razão ou julgavam que não poderiam conseguir, e por isso, nem sequer tentavam a mudança. Foi impossível ouví-los sem lembrar as palavras de Paulo Freire sobre a necessidade do educador de ouvir a verdade do educando caso pretenda romper com a postura do ensino tradicional (FREIRE, 1997b).

De posse da situação levantada apresentamos o currículo da matéria e aplicamos uma adaptação de uma ferramenta usada no coaching chamada Roda da vida. Batizamos a adaptação de Roda do Conhecimento. Ela fomenta perguntas sobre o contexto do autor, sua biografia, suas obras, os conceitos defendidos, etc. A partir dela os alunos começaram a descobrir o quanto eles desconheciam do autor ou do tema que precisaríamos trabalhar. A Roda do Conhecimento visa não ao constrangimento do aluno que não sabe, mas à promoção do encontro dele com aquilo que ainda lhe é desconhecido, tal qual a forma como Sócrates travava seus interlocutores, buscando deles o máximo de informação até que, esgotada todas as possibilidades, fosse possível construir um saber sólido (PLATÃO, 1980). Tal técnica ficou conhecida como Maiêutica, uma alusão ao nascimento de criança. Seria, portanto, um parto do saber. A cada tentativa de resposta, mesmo que não bem sucedida, é dado um feedback positivo, estimulando o aluno a continuar tentando e a não desistir ou se achar inferior ou incapaz por não ter acertado na primeira vez. Essa ferramenta é conhecida no coaching como Patrocínio Positivo. Ela encontra eco na postura freiriana de respeitar o aluno na sua integralidade, entendendo ser ele um ser em um processo, de modo que cada etapa tem o seu valor. 
Se não se leva em consideração as condições em que os alunos vêm existindo, se não se reconhece a importância do conhecimento que eles adquiriram na sua experiência de vida, não é possível se afirmar que há respeito à dignidade e ao processo de formação da sua identidade que começou antes da sua chegada ao ambiente escolar, como afirma Freire:

(...) conhecimentos de experiência feitos com que chegam à escola. $\mathrm{O}$ respeito devido à dignidade do educando não me permite subestimar, pior ainda, zombar do saber que ele traz consigo para a escola (FREIRE, 1997b, p. 37).

No início do processo, quando o aluno assumiu conscientemente o seu não saber, firmamos um pacto de parceria pelo qual ele se comprometeu em, com a minha ajuda, construir seu repertório de saber. Essa parceria é firmada utilizando outra ferramenta de coaching chamada de Escala. Na Escala, pergunto ao aluno o quanto, em uma escala de 0 a 10, ele está comprometido com a parceria e o seu crescimento. Caso ele se dê uma nota abaixo de 10 , pergunto o que ele ou eu podemos fazer para que chegue a 10 . As perguntas visam revelar os problemas que possam atrapalhar o crescimento do aluno a fim de ajudá-lo a contorná-los.

Todo esse processo tem como objetivo, em primeiro lugar, devolver no aluno o poder de escolha do seu destino, desmistificando a sociedade e tirando dela seu poder de produtora de realidade e tornando-a uma consequência dos atos dos indivíduos, tornando-os protagonistas da própria história.

\section{Considerações finais}

Se nada ficar destas páginas, algo, pelo menos, esperamos que permaneça: nossa confiança no povo. Nossa fé nos homens e na criação de um mundo que seja menos difícil de amar. (Paulo Freire - Pedagogia do oprimido)

O uso da técnica de coaching durante as aulas de Sociologia, nas turmas de Ensino Médio, produziu mais do que uma apropriação de conhecimentos. Produziu um clima favorável para o processo de ensino-aprendizagem motivado pela elevação da autoestima da turma que se reconheceu como protagonista da construção do seu saber. 
Essa nova postura tem resgatado a autoconfiança e construído outro olhar para sua condição de aluno de escola pública.

O levantamento da condição atual do aluno em relação ao conteúdo da matéria, através das ferramentas descritas no trabalho e a tomada de consciência do mau uso que ele faz do tempo, facilitam a objetivação da razão de ser da aula e ajudam a construir o caminho necessário para que se alcance o objetivo primeiro que é a aquisição do saber sobre Sociologia e a consequente aprovação.

Concluo este artigo afirmando que o coaching refina aquilo que está na base do ser professor que é a atitude de ajudar alguém a sair do seu estado atual em direção a um estado desejado; o que, no caso em questão, é a apropriação dos conteúdos da disciplina de Sociologia, mas produzindo, no aluno, um sentido maior do que apenas se preparar para uma prova bimestral.

\section{Referências}

BOURDIEU, Pierre; PASSERON, Jean Claude. A reprodução: elementos para uma teoria do sistema de ensino. 3. ed. Rio de Janeiro: Livraria Francisco Alves, 1992.

. Questões de Sociologia. São Paulo: Annablume, 2007.

CELESTINO, Sílvio. A origem da palavra coach. Disponível em http://oglobo.globo.com/blogs/elevador/posts/2009/07/16/a-origem-da-palavra-coach-

205392.asp. Acesso em: 12. Set. 2015

ELIAS, Norbert. A Sociedade dos Indivíduos. Rio de Janeiro: Zahar, 1994.

FREIRE, Paulo. Pedagogia da autonomia. São Paulo: Paz e Terra, 1997ª . Pedagogia do oprimido. 4. ed. Rio de Janeiro: Paz e Terra, $1997 \mathrm{~b}$.

GEERTZ, Clifford. A interpretação das culturas. Rio de Janeiro: LTC, 2008.

LAHIRE, Bernard. Sucesso escolar nos meios populares: as razões do improvável. São Paulo: Ática, 2004.

MARQUES, José Roberto. Coaching - conceito e significado. Disponível em: http://www.ibccoaching.com.br/tudo-sobre-coaching/coaching/coaching-conceito-esignificado. Acesso em: 20. set. 2015.

PlATÃO. A Defesa de Sócrates. Abril Cultural, Coleção Os Pensadores, 1980. Disponível em: https://www.metodista.br/eduCommons/faculdade-de-humanidades-e- 
direito/modulo-02-logica-e-filosofia-antiga/aula-2-historia-da-filosofia-antiga-socratese-o-problema-socratico/a-defesa-de-socrates. Acesso em: 25.out.2016

ROUSSEAU, Jean Jacques. Projeto para a educação do senhor de Sanite-Marie. Tradução: Dorothée de Bruchard. Florianópolis: Paraula, 1995.

Emílio ou da educação. Tradução: Roberto Leal Ferreira. São Paulo: Martins Fontes, 2004.

SETTON, Maria da Graça Jacintho. A teoria do habitus em Pierre Bourdieu: uma leitura contemporânea. Revista Brasileira de Educação. Rio de Janeiro, p. 60-70. maio 2002.

WHITMORE, John. Coaching para performance: aprimorando pessoas, desempenhos e resultados: competências pessoais para profissionais. $3^{a}$ reimpressão. Rio de Janeiro: Qualitymark Editora Ltda, 2012.

Recebido em 29 de setembro de 2015.

Aprovado em 18 de setembro de 2016. 